\title{
A inibição do sistema conservante de duas emulsões o/a por polissorbato 80
}

\author{
Inhibition of the preservative system of two o/w emulsions by polysorbate 80
}

Recebido em: $\quad 09 / 10 / 2015$

Aceito em: $\quad 27 / 11 / 2015$
Thalles Yuri Loiola VASCONCELOS, Débora Patrícia

Feitosa MEDEIROS, Aristides Ávilo do NASCIMIENTO

Instituto Superior de Teologia Aplicada. Rua Coronel Antonio Rodrigues

Magalhães, Bairro Dom Expedito Lopes, 359. Sobral, Ceará, Brasil. E-mail:

farmacia.escola@inta.edu.br

\section{ABSTRACT}

The inhibition of growth of microorganisms due to the bacteriostatic or fungistatic effect of the formulation may cause a false-negative result in microbiological analysis. Thus, the evaluation of the inhibitory capacity of the preservatives present in the sample is critical to an effective microbiological evaluation. The tests were performed to prove the absence of the inhibitory effect on the growth of microorganisms due to the inhibitory activity of these components. Inhibition of the formulation preservative effect was carried out by two methods: by the addition of $0.4 \%$ polysorbate 80 and dilution. The sample was prepared using $10 \mathrm{~g}$ of each sample in $90 \mathrm{~mL}$ of $0.9 \%$ saline, resulting in a 1:10 dilution. Also, it was added $0.4 \%$ polysorbate 80 in saline solution to neutralize the parabens and imidazolidine in the formulations. The neutralization of the inhibitory effect was performed by using $0.4 \%$ polysorbate 80 and 1:10 dilution. It observed the growth of the following microorganisms: Staphylococcus aureus, Salmonella typhimurium, and Pseudomonas aeruginosa in all samples and the positive control, meaning the inactivation of the inhibitory effect of preservatives

Keywords: cosmetic; cosmetic additives; cosmetic stability; parabens; polysorbates

\section{RESUMO}

A inibição do crescimento de microrganismos devido ao efeito bacteriostático ou fungistático da formulação pode ocasionar um resultado falso-negativo na análise microbiológica. Assim, a avaliação da capacidade inibitória dos conservantes presentes nas amostras é fundamental para uma avaliação microbiológica eficaz. Os ensaios foram realizados com objetivo de comprovar a ausência do efeito inibitório no crescimento de microrganismos decorrente da atividade inibitória desses componentes. A inibição do efeito conservante da formulação foi realizada utilizando dois métodos: por adição de polissorbato 80 a $0,4 \%$ e por diluição. Foram utilizados $10 \mathrm{~g}$ de cada amostra em $90 \mathrm{~mL}$ de salina a $0,9 \%$, resultando em uma diluição 1:10. Foi adicionado também polissorbato 80 a $0,4 \%$ na solução salina com objetivo de neutralizar os parabenos e imidazolidinilureia nas formulações. A neutralização do efeito inibitório foi realizada usando polissorbato 80 a 0,4 \% e da diluição 1:10. Foi observado o crescimento dos seguintes micro-organismos: Staphylococcus aureus, Salmonella typhimurium e Pseudomonas aeruginosa em todas as amostras e no controle positivo, significando a inativação do efeito inibitório das substâncias conservantes.

Palavras chave: cosméticos; aditivos em cosméticos; estabilidade de cosméticos; parabenos; polissorbatos 
INTRODUÇÃO

O mercado brasileiro na área de cosméticos está entre os mais importantes do mundo, caracterizando uma população vaidosa que considera os produtos cosméticos como essenciais. Esse segmento teve início a partir da segunda metade do século XX até chegar entre os três maiores mercados do mundo do início do século XXI $(1,2)$.

Segundo a Associação Brasileira da Indústria de Higiene Pessoal, Perfumaria e Cosméticos (3), a população brasileira é uma das mais vaidosas, o que justifica a posição do Brasil (9,5 \%) atrás apenas da China $(9,7 \%)$ e dos Estados Unidos da América (16,1 \%) no que se refere a esse bem de consumo, estando à frente de países como Japão $(8,6 \%)$, Alemanha (4,2\%) e França (3,7\%).

Os avanços científicos e tecnológicos em recentes décadas permitiram um melhor desenvolvimento e controle desses produtos. Sua fabricação baseia-se no binômio "eficácia e segurança", pois além de desempenhar suas propriedades, esses produtos devem ter segurança no seu uso, sem causar efeitos indesejáveis $(4,5)$.

E para garantir que esses requisitos sejam cumpridos, é necessário executar testes para avaliar as condições físicas, químicas e microbiológicas (6). A qualidade de cosméticos e produtos farmacêuticos está relacionada com o grau de conformidade com os requisitos e padrões mínimos estabelecidos pela Resolução da Diretoria Colegiada (RDC) $n^{\circ} 481$, de 23 de setembro de 1999, que estabelece os limites microbiológicos para produtos de higiene pessoal, cosméticos e perfumes, descritos no Quadro $1(7,8)$.

Para a obtenção de cosmético de boa qualidade microbiológica torna-se necessário não só a ausência de microrganismos patogênicos, mas também a garantia que a carga microbiana não patogênica seja a menor possível e que as concentrações dos agentes estejam dentro das concentrações legalmente permitidas.

Para atingir uma boa estabilidade microbiológica é fundamental que os mecanismos responsáveis pela contaminação sejam identificados. Os meios de contaminação mais comuns são: a água, o ambiente, o ar, a matéria-prima, os equipamentos e, principalmente, o manipulador $(8,9)$.

A água é a principal matéria-prima da indústria cosmética (10) e a sua presença, além de componentes orgânicos na formulação, favorece o crescimento microbiológico. Em alguns casos, estes afetam a estabilidade do produto, devido à presença de íons, bem como a contaminação microbiana, o que justifica a avaliação microbiológica desses produtos (11).

A fim de garantir a qualidade microbiológica ideal de produtos cosméticos, a Farmacopeia Brasileira $5^{\text {a }}$ edição preconiza a realização de alguns testes, entre eles a contagem microbiana e a identificação de micro-organismos patógenos (12). A contagem microbiana procura determinar o total número de micro-organismos mesófilos aeróbios totais. A identificação de microrganismos patógenos apenas identifica crescimento ou ausência de crescimento de determinados micro-organismos. Além disso, outro fator importante é que o método utilizado seja validado para cada produto analisado $(12,13,14)$. Porém, antes da realização dos testes microbiológicos, é necessária a neutralização de substâncias conservantes ou antimicrobianas que possam estar presentes na amostra. Esses conservantes são utilizados em produtos cosméticos não estéreis para evitar o crescimento microbiológico. Entre os mais conhecidos estão os parabenos (metilparabeno e propilparabeno), cloreto de benzalcônio, fenóis, entre outros (15).

Quadro 1. Parâmetros de controle microbiológico para os produtos de higiene pessoal, cosméticos e perfume, de acordo com a RDC $n^{\circ}$ $481 / 1999(7)$

\begin{tabular}{|c|c|c|}
\hline Tipo & $\begin{array}{c}\text { Área de aplicação e faixa } \\
\text { etária }\end{array}$ & Limites de aceitabilidade \\
\hline I & $\begin{array}{l}\text { Produtos para uso infantil; } \\
\text { rodutos para área dos olhos; } \\
\text { produtos que entram em contato } \\
\text { com mucosas }\end{array}$ & $\begin{array}{l}\text { a) Contagem de microrganismos mesófilos aeróbios totais, não mais que } \\
10^{2} \mathrm{UFC} / \mathrm{g} \text { ou mL. Limite máximo } 5 \times 10^{2} \mathrm{UFC} / \mathrm{g} \text { ou } \mathrm{mL} \\
\text { b) Ausência de Pseudomonas aerugiosa em } 1 \mathrm{~g} \text { ou } 1 \mathrm{~mL} \\
\text { c) Ausência de Staphylococcus aureus em } 1 \mathrm{~g} \text { ou } 1 \mathrm{~mL} \\
\text { d) Ausência de Coliformes totais e fecais em } 1 \mathrm{~g} \text { ou } 1 \mathrm{~mL} \\
\text { e) Ausência de Clostridium sulfito redutor em } 1 \mathrm{~g} \text { (exclusivamente para } \\
\text { talcos). }\end{array}$ \\
\hline II & $\begin{array}{l}\text { Demais produtos susceptíveis à } \\
\text { contaminação microbiológica }\end{array}$ & $\begin{array}{l}\text { a) Contagem de micro-organismos mesófilos aeróbios totais, não mais que } \\
10^{3} \mathrm{UFC} / \mathrm{g} \text { ou } \mathrm{mL} \text {. Limite máximo } 5 \times 10^{3} \mathrm{UFC} / \mathrm{g} \text { ou } \mathrm{mL} \\
\text { b) Ausência de Pseudomonas aeruginosa em } 1 \mathrm{~g} \text { ou } 1 \mathrm{~mL} \\
\text { c) Ausência de Staphylococcus aureus em } 1 \mathrm{~g} \text { ou } 1 \mathrm{~mL} \\
\text { d) Ausência de Coliformes totais e fecais em } 1 \mathrm{~g} \text { ou } 1 \mathrm{~mL} \\
\text { e) Ausência de Clostrídium sulfito redutor em } 1 \mathrm{~g} \text { (exclusivamente para } \\
\text { talcos) }\end{array}$ \\
\hline
\end{tabular}


Diversas substâncias possuem a função de neutralizar determinados agentes conservantes em produtos cosméticos e farmacêuticos. Para a neutralização dos parabenos, o compêndio nacional indica a utilização de polissorbato 80 em substituição ao polissorbato 20 preconizado pelo compêndio americano e com concentração 10 vezes inferior $(0,4 \% \mathrm{p} / \mathrm{v})$. Os polissorbatos, além de possuir ação neutralizante dos conservantes, são agentes emulsificantes e são amplamente utilizados na produção de diversos produtos cosméticos $(11,13,16)$. A neutralização de substâncias antimicrobianas presentes na amostra é necessária uma vez que a presença de conservantes pode inibir o crescimento microbiano, impedindo desse modo a determinação precisa do número total de colônias presente na amostra, ou a presença de microrganismos patógenos (17).

Assim, a avaliação do potencial do polissorbato 80 para neutralizar o agente conservante é um fator que vai provar a eficácia da análise microbiológica.

O objetivo do presente trabalho foi avaliar o efeito neutralizante do polissorbato 80 a $0,4 \%$ em amostras de duas emulsões óleo-em-água, para posterior avaliação da qualidade microbiológica de cosmético nos quais são empregados.

\section{MATERIAIS E MÉTODOS}

O objeto deste estudo foram dois tipos de emulsões óleo-em-água, uma do tipo aniônica e outra do tipo não iônica. Os componentes de cada uma das formulações estão descritos na Tabelas 1 .

\begin{tabular}{|l|c|c|}
\hline \multirow{2}{*}{\multicolumn{1}{|c|}{ componentes }} & \multicolumn{2}{c|}{$(\%)$} \\
\cline { 2 - 3 } & NI & A \\
\hline fase aquosa & 0,1 & 0,1 \\
\hline EDTA sódico (Dinâmica, Lote: G0743) & 0,2 & 0,2 \\
\hline metilparabeno (Mcassab, Lote: Ah1511) & 75,9 & 69,9 \\
\hline água purificada & 3,0 & 3,0 \\
\hline glicerina (Anastácio, Lote: 17294) & & \\
\hline fase oleosa & 0,1 & 0,1 \\
\hline $\begin{array}{l}\text { butilidroxitolueno (Dinâmica, Lote: } \\
\text { 57235) }\end{array}$ & 0,1 & 0,1 \\
\hline propilparabeno (Farmos, Lote: Jj1911) & 16,0 & 16,0 \\
\hline $\begin{array}{l}\text { cera auto-emulsionante não iônica } \\
\text { (Farmos, Lote: Pe41184) }\end{array}$ & 2,0 & 8,0 \\
\hline $\begin{array}{l}\text { estearato de octila (AQIA, L0TE: } \\
\text { PF40621) }\end{array}$ & 2,0 & 2,0 \\
\hline $\begin{array}{l}\text { ciclometicona (Emfal, Lote: } \\
\text { 220200190/13) }\end{array}$ & \\
\hline $\begin{array}{l}\text { fase complementar } \\
\text { solução de imidazolidinilureia 50\% } \\
\text { (Akema, Lote: A15m705) }\end{array}$ & 0,6 & 0,6 \\
\hline
\end{tabular}

Obtenção e Padronização de Suspensão de Patógenos: Em cada tubo contendo $5 \mathrm{~mL}$ de caldo BHI (BD BBL Brain Heart Infusion, Lote: 3092285) previamente esterilizado foram inoculadas as cepas dos seguintes microrganismos: Staphylococcus aureus (ATCC 6538), Pseudomonas aeruginosa (ATCC 9027) e Salmonella typhimurium (ATCC 14028), provenientes de cultura em estoque. Em seguida os tubos foram incubados a $37{ }^{\circ} \mathrm{C}$ durante 24 horas.

Preparo das amostras: Foram preparados 6 tubos com $8 \mathrm{~mL}$ de solução salina $0,9 \%$ e polissorbato $800,4 \%$; 3 tubos com $9 \mathrm{~mL}$ de solução salina $0,9 \%$ e polissorbato 80 $0,4 \%$; e $90 \mathrm{~mL}$ de solução salina $0,9 \%$ e polissorbato 80 0,4 $\%$ em frasco reagente. Após esse procedimento, os tubos e o frasco reagente contendo os diluentes foram esterilizados por calor úmido em autoclave por 15 minutos a $121^{\circ} \mathrm{C}$.

Foram adicionados $10 \mathrm{~g}$ de cada emulsão, separadamente, em bequer, e adicionados $90 \mathrm{~mL}$ de solução salina 0,9 $\%$ e polissorbato $800,4 \%$ previamente esterilizados, produzindo uma diluição 1:10 após agitação constante. O método empregado foi seguido conforme descrito na Farmacopeia Brasileira 5a ed. (12), diferindo apenas em relação aos componentes neutralizantes (foi utilizado apenas o polissorbato 80 $0,4 \%)$.

Avaliação da atividade anibitória: uma alíquota de $1 \mathrm{~mL}$ da suspensão de $S$. aureus foi transferida para dois tubos, cada um contendo $8 \mathrm{~mL}$ de solução salina $0,9 \% \mathrm{e}$ polissorbato $800,4 \%$. Aos tubos foi adicionado $1 \mathrm{~mL}$ de cada emulsão (aniônica e não-iônica) adiluída na proporção 1:10, separadamente. O mesmo procedimento foi realizado para $S$. typhimurium e $P$. aeruginosa. Como controles positivos, $1 \mathrm{~mL}$ da suspensão de cada um dos microrganismos patogênicos foi transferida, separadamente, para tubos de ensaio, cada um contendo $9 \mathrm{~mL}$ de solução salina $0,9 \%$ e polissorbato $800,4 \%$.

Os tubos foram incubados a $37^{\circ} \mathrm{C}$ por 24 horas em estufa. Ao término do período de incubação, os resultados foram lidos pela presença ou não de turvação, indicando crescimento pela turvação (microrganismos ativos) ou ausência de crescimento pela ausência de turvação (microrganismos inativados).

\section{RESULTADOS E DISCUSSÃO}

O resultado do teste de avaliação da capacidade inibitória dos conservantes das emulsões revelou o crescimento de microrganismos patogênicos nas emulsões diluídas e no controle positivo. Desse modo o polissorbato $800,4 \%$, juntamente com a diluição 1:10 das amostras, se mostrou adequado para neutralizar a ação dos parabenos e da imidazolidinilureia presentes nas formulações.

A inibição do crescimento microbiano devido ao efeito bacteriostático ou fungistático de componentes presentes na formulação pode ocasionar resultado falso-negativo nas técnicas de contagem microbiana, dependentes da 
formação de colônias ou da presença de turvação para a detecção de contaminantes.

Nesse trabalho foram utilizados dois recursos para a neutralização do sistema conservante das duas emulsões: a diluição (1:10), visando a neutralização da imidazolidinilureia e a adição, à suspensão salina, de substâncias inativantes específicas, tais como o polissorbato $800,4 \%$ $(\mathrm{m} / \mathrm{v})$, visando a neutralização química dos parabenos (metilparabeno e propilparabeno), contidos nas formulações. Considerando a não-interferência das substâncias neutralizadoras, assim como da diluição utilizada, no crescimento microbiano, a ausência da atividade inibitória dos componentes antimicrobianos do produto no método de identificação adotado pode ser constatada na Tabela 2, para a diluição 1:10 e para todos os microrganismos empregados.

Tabela 2. Avaliação do crescimento bacteriano nas emulsões aniônica e não iônica adicionadas de solução de polissorbato 80 0,4\%

\begin{tabular}{|c|c|c|c|c|}
\hline Microrganismos & $\begin{array}{c}\text { Creme } \\
\text { Base } \\
\text { Aniônico }\end{array}$ & $\begin{array}{c}\text { Creme } \\
\text { Base } \\
\text { Não- } \\
\text { Iônico }\end{array}$ & $\begin{array}{c}\text { Controle } \\
\text { Positivo }\end{array}$ & $\begin{array}{c}\text { Controle } \\
\text { Negativo }\end{array}$ \\
\hline $\begin{array}{c}\text { Staphylococcus } \\
\text { aureus }\end{array}$ & $\mathrm{C}$ & $\mathrm{C}$ & $\mathrm{C}$ & $\mathrm{N}$ \\
\hline $\begin{array}{c}\text { Pseudomonas } \\
\text { aeruginosa }\end{array}$ & $\mathrm{C}$ & $\mathrm{C}$ & $\mathrm{C}$ & $\mathrm{N}$ \\
\hline $\begin{array}{c}\text { Salmonella } \\
\text { typhimurium }\end{array}$ & $\mathrm{C}$ & $\mathrm{C}$ & $\mathrm{C}$ & $\mathrm{N}$ \\
\hline
\end{tabular}

C: houve crescimento bacteriano (turvação); N: Não houve crescimento bacteriano (ausência de turvação)

Foi observada a presença de turvação, indicativo de crescimento microbiano, em todas as amostras contendo creme base aniônico e creme base não-iônico. As amostras foram comparadas ao controle positivo, sendo possível confirmar o crescimento de microrganismos patogênicos.

Alguns autores têm comprovado a eficácia do polissorbato $80 \mathrm{em}$ diversas concentrações na neutralização de conservantes como o metilparabeno e o propilparabeno $(18,19)$. Em alguns estudos, como o estudo de Bou-Chacra e Ohara (2003) e o estudo de Marques e Moreira (2009), a associação de polissorbato $80 \mathrm{com}$ a lecitina de soja é utilizada $(9,13)$.

De forma semelhante ao presente trabalho, Shaqra e Al-Shawagfeh (2012), neutralizaram a ação dos conservantes em uma preparação antiácida utilizando o polissorbato 80 0,5\% (18). Marques e Moreira (2009) utilizaram uma associação de polissorbato $803 \%$ e lecitina $0,3 \%$ para inativação dos conservantes presentes em formulações fotoprotetoras (9). De forma semelhante, Sharif-Abad e cols (2015) utilizaram a associação de polissorbato $803 \%$ e lecitina $0,5 \%$ para neutralização do efeito antimicrobiano de cinco amostras de protetores solares, ambos obtendo neutralização adequada (20). Em estudo de Garcia (2014), foi utilizado também o polissorbato 80 para inativação dos parabenos para posterior análise microbiológica de uma loção fotoprotetora (21).

Bou-Chacra e Ohara (2003) neutralizaram os conservantes em preparações cosméticas de base lipofílica utilizando o polissorbato $204 \%$ e lecitina $0,5 \%$ (13). Em contrapartida, Ramos (2010), para a neutralização química, utilizou o polissorbato $800,4 \%$ e lecitina $0,5 \%$ em diluição $1: 10$. Porém essa metodologia não foi satisfatória para neutralização dos conservantes de duas formulações estudadas. Desse modo, a concentração dos neutralizantes foi alterada para polissorbato $803 \%$ e lecitina de soja $0,3 \%$, além de diluição $1: 100$, sendo esta mais adequada à inativação dos conservantes presentes nas duas formulações. Shaqra e cols (2001) utilizaram o polissorbato 80 $1 \%$ para neutralização dos conservantes presentes em 16 formulações diferentes de xampus. De forma semelhante, Moura e cols (2011) utilizaram o polissorbato $801 \%$ em associação com tampão fosfato de potássio $\mathrm{pH}$ 7,2 para a neutralização dos parabenos de uma amostra de gel contendo extrato hidroalcoólico de Schinus terebinthifolius (23).

\section{CONCLUSÃO}

Os testes realizados indicaram que o método utilizado foi adequado para neutralizar a ação dos conservantes, pois foi visível o crescimento microbiano através da turvação. É importante a utilização de substâncias para neutralizar a ação de componentes de formulações que apresentem atividade antimicrobiana. Após a confirmação da capacidade inibitória do polissorbato 80 , é possível realizar outras avaliações microbiológicas com maior confiabilidade, pois foi comprovado que os componentes conservantes das amostras estão neutralizados e não irão resultar em um desfecho falso-negativo. Com referência ao método adotado, a diluição 1:10 foi considerada adequada para a pesquisa dos seguintes microrganismos patogênicos específicos: Salmonella typhimurium, Pseudomonas aeruginosa e Staphylococcus aureus. Dessa forma, houve crescimento microbiano nas duas bases na presença de polissorbato 80 $0,4 \%$, apresentando assim, eficácia na neutralização dos parabenos e da imidazolidinilureia por meio de neutralização química e pela diluição.

\section{AGRADECIMENTOS}

Deixo expressos os agradecimentos à Farmácia Escola e ao Núcleo de Bioprospecção e Experimentação Molecular Aplicada (NUBEM) das Faculdades INTA. 
1. Capanema LXL, Velasco LOM, Filho PLP, Noguti MB. Panorama da Indústria de Higiene Pessoal, Perfumaria e Cosméticos. BNDES Setorial, 2007;(25):132-56.

2. CRF-PR. Manual de Diretrizes Indústria Cosmética. Comissão de Industria Farmacêutica. Conselho Regional de Farmácia do Estado do Paraná.2012. 59p.

3. ABIHPEC. Panorama do setor de Higiene Pessoal, Perfumaria e Cosméticos. Associação Brasileira da Indústria de Higiene Pessoal, Perfumaria e Cosméticos. 2014. 23p.

4. Carvalho A, Meurer V, Pinto T, Yamamoto C. Controle de qualidade microbiológica de produtos farmacêuticos, cosméticos e fitoterápicos produzidos na Zona da Mata. In: Anais do $2^{\circ}$ Congresso Brasileiro de Extensão Universitária. 2004. Belo Horizonte: UFMG; 2004.

5. Heemann ACW, Guarda CC, Paula D, Siebenrok EN, Bareta GMS, Justi JS, Chociai JG, Semes S, Reple SIF. Guia da profissão farmacêutica: Indústria de produtos de higiene pessoal, cosméticos e perfumes. Conselho Regional de Farmácia do Estado do Paraná. $1^{a}$ ed. 2010. 23p

6. Itah AY, Udokpoh AE, Ofum MU. Bacteriological quality of some pharmaceutical products marketed by drugs vendors in Uyo, Nigeria. Afr. J. Health Sci. 2004. 11(34):128-133. DOI: 10.4314/ajhs.v11i3.30789.

7. BRASIL. Agência Nacional de Vigilância Sanitária. Resolução RDC nº 481, de 23 de setembro de 1999. Estabelece os parâmetros de controle microbiológico para os produtos de higiene pessoal, cosméticos e perfumes.

8. Silva CHPM, Netto H. Contaminação Microbiana em produtos Cosméticos e Seu Controle. Science News. 2002. 1(2):5-7.

9. Marques MC, Moreira LM. Análise microbiológica de protetor solar manipulado nas farmácias magistrais do município de Ipatinga/MG. Rev. Bras. Farm. 2009. 90(1):137143.

10. Rebello TFS. Boas Práticas. Água. Cosmet. Toiletries. 2001. 13(3):24.

11. Anvisa. Guia de estabilidade de produtos cosméticos. Série Qualidade em Cosmético.Vol. 1. Agência Nacional de Vigilância Sanitária. 2004. 52p.

12. BRASIL. Farmacopeia Brasileira. $5^{\text {a }}$ edição, Vol. 1 e 2. Agência Nacional de Vigilância Sanitária. Brasília: Anvisa, 2010.

13. Bou-Chacra NA, Ohara MT. Validação de método para avaliação da qualidade sanitária de preparação cosmética de base lipófila. Rev. Bras. Cienc. Farm. 2003. 39(2):18594. DOI: $10.1590 / \mathrm{S} 15163322003000200009$

14. USP. The United States Pharmacopeia Convention. United States Pharmacopeia. 30. ed. Rockville, 2007.

15. Tariq M, Naveed A, Ali KB, Akhtar R, Shoaib KHM. Fabrication, physicochemical characterization and preliminary efficacy evaluation of a W/O/W multiple emulsion loaded with 5\% green tea extract. Braz. J. Pharm. Sci. 2013. 49(2):341-9. DOI: 10.1590/S1984-82502013000200016.

16. Pramanick S, Singodia D, Chandel V. Excipient Selection In Parenteral Formulation Development. Pharm Times. 2013. 45(3):65-77.

17. Andrade APA, Oliveira SB, Araújo CMC, Grangeiro PM, Ramos JS, Vieira SV. Development and validation of a microbial counting method for mebendazole oral suspension. Braz. J. Pharm. Sci. 2011. 47(3):555-63. DOI: 10.1590/S19842502011000300013

18. Shaqra QMA, Al-Shawagfeh M. Assessment of the harmonized preservatives effecacy test in oral liquid pharmaceutical preparations using reference and none reference test microorganisms. Asian J Pharm Clin Res. 2012. 5(2):141-4.

19. Shaqra QMA, Mashni Y, Al-Momani W. Microbiological quality and in use preservative capacity of shampoo preparations manufactured in Jordan. Jordan. J. Biol. Sci. 2011. 4(2):113-8.

20. Sharif-Abad NS, Saeedi M, Enayatifard R, Morteza-Semnani K, Akbari J. Evaluation of microbial content of some sunscreen creams in Iran's Market. Int J Pharm Biomed Res. 2015. 1(2):30-4.

21. Garcia LU. Avaliação da estabilidade físico-química, microbiológica e determinação do FPS de uma loção fotoprotetora. (Trabalho de Conclusão de Curso). Fortaleza: Universidade Federal do Ceará: Curso de Farmácia, Faculdade de Farmácia, Odontologia e Enfermagem. 2014.

22. Ramos SVV. Validação da metodologia analítica aplicada ao controle microbiológico de formas farmacêuticas líquidas e determinação da eficácia de conservantes (Dissertação). Recife: Universidade Federal de Pernambuco, Departamento de Ciências Farmacêuticas. 2010.

23. Moura TFAL, Raffin FN, Santos ALR. Evaluation of a preservative system in a gel containing hydroalcoholic extract of Schinus terebinthifolius. Rev. Bras. Farmacogn. 2011. 21(3):532-6. DOI:10.1590/S010295X201100500010 